\title{
Staged Management of Bladder Exstrophy
}

\author{
Jamal S. Kamal, FRCSI, FACS \\ Department of Surgery, Faculty of Medicine, \\ King Abdulaziz University, Jeddah, Saudi Arabia \\ drjamalkamal@yahoo.com
}

\begin{abstract}
Bladder exstrophy or as an erroneously known as ectopia vesica is a rare congenital malformation of the lower part of the abdomen and the genital area. It involves the urinary bladder, abdominal wall, pubic bones and the external genitalia. It requires functional reconstruction, which is often done as a single or in multiple stages; the aim of management is to preserve kidney functions, maintain urinary continence, achieve sexual function and near normal appearance of the external genitalia. At King Abdulaziz University Hospital in Jeddah, Saudi Arabia, twelve cases of bladder exstrophy (the classical type) were seen and managed between October 1990 and December 2007. All cases were managed in multiple stages. In this paper reviewed the experience and the results obtained in the management of bladder exstrophy. Out of the twelve cases, four patients achieved urinary continence and seven were incontinent (dry period less than three hours) and one late death. Other complications were also seen and will be discussed during this report.
\end{abstract}

Keywords: Bladder exstrophy, Staged repair, Reasonable outcome.

\section{Introduction}

Bladder exstrophy is a rare congenital birth defect where the bladder wall is turned inside out, so that the ureteric orifices and the interior bladder wall are exposed. The urethra and external genitalia are not completely formed. The anal verge and the vagina in females appear to be displaced forward, in addition to widely separated pubic bones (Fig. 1). The first

\author{
Correspondence \& reprint request to: $\quad$ Dr. Jamal S. Kamal \\ P.O. Box 80215, Jeddah 21589 Saudi Arabia
}

Accepted for publication: 03 March 2009. Received: 24 March 2008. 
mention of this abnormality was seen in an Assyrian tablet from $2000 \mathrm{BC}$ preserved in the British museum. It was first described by Grofenberg in $1597^{[1,2]}$.

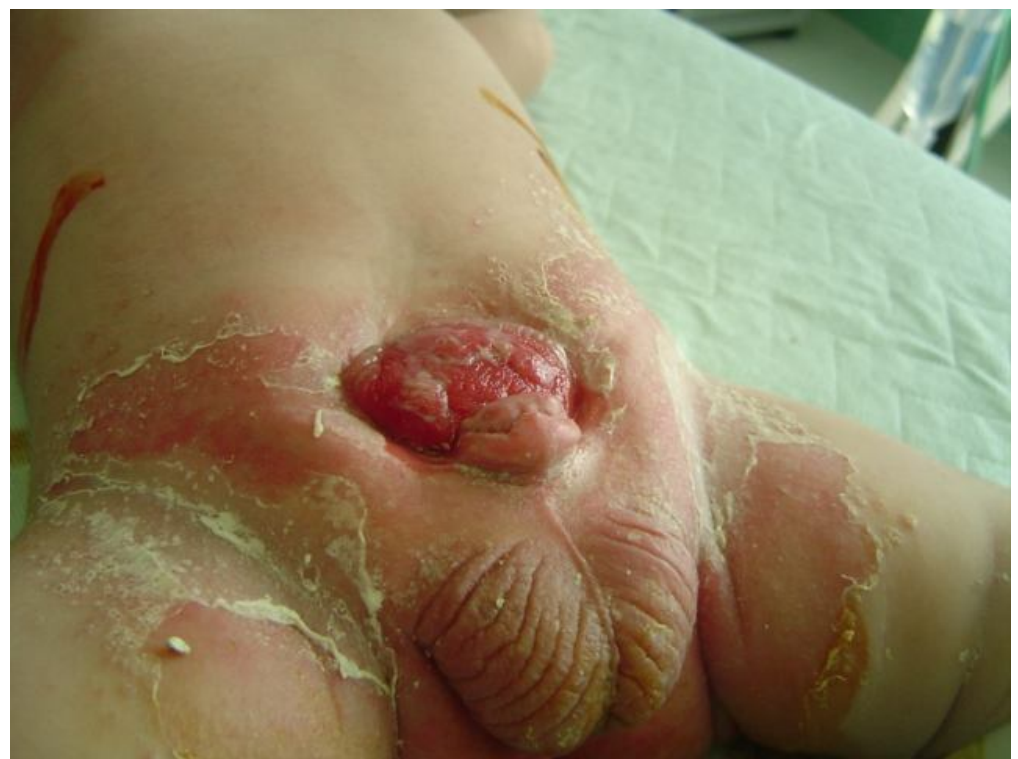

Fig. 1. A classical form of bladder exstrophy.

Bladder exstrophy was thought to occur as a result of an abnormal over-development of the cloacal membrane, (Marshall and Muecke $)^{[1]}$. The abnormality occurs in a range of spectrum, from epispadias to cloacal exstrophy ${ }^{[3]}$. The estimated incidence of bladder exstrophy is 1:30000-1:50000 live births with a 2:1 male/female ratio. There is no clear evidence for genetic predisposition of this anomaly, however, it can re-occur in the same family by a ratio of 1:100 and there is 500 times greater chance of having bladder exstrophy in the offspring of individuals having bladder exstrophy or epispadias than in the general population ${ }^{[1]}$.

Bladder exstrophy can be associated with other anomalies like spinal defects, but in general they are confined to structures around the open bladder and urethra as vesicoureteric reflux, inguinal hernias, undescended testes, rectal prolapse, and foreshortened penis in males and stenosed vagina with bifid clitoris in females. The upper urinary tract is usually spared. The main problems associated with this abnormality are: Skin irritation from continuous uncontrolled urine leakage and ascending urinary infection. It is managed surgically in a single or multiple stages. 
These involved closure of the bladder and abdominal wall defects, tightening of the bladder neck, and genitoplasty. The procedures can be facilitated by pelvic osteotomy ${ }^{[4]}$. The overall results of the surgical management are still beyond satisfaction with no definite solution and urinary diversion in some cases are warranted ${ }^{[5,8]}$.

\section{Materials and Methods}

Between October 1990 and December 2007, twelve cases of classical bladder exstrophy were seen and managed at King Abdulaziz University Hospital (KAUH) Jeddah, 9 males and 3 females. Four patients presented at birth; five at age between 5 and 20 days; three patients presented late at the ages of 6 months, 18 months and 2 years. Several associated anomalies were seen in these patients, they are summarized in Table 1.

Table 1. Associated anomalies.

\begin{tabular}{l|c}
\hline \multicolumn{1}{c|}{ Associated Anomalies } & No. of Cases \\
\hline Bilateral inguinal hernia & 2 \\
\hline Right inguinal hernia & 1 \\
\hline Undescended testes & 1 \\
\hline Duplex ureter & 1 \\
\hline Ventricular septal defect & 1 \\
\hline Microtia & 1 \\
\hline Nystagmus & 1 \\
\hline Single kidney & 1 \\
\hline
\end{tabular}

All were managed in planned three stages. In the first stage, functional closure of the bladder wall with tightening of the bladder neck, Young-Dees-Leadbetter technique. No osteotomy was added for those presented before three days (Fig. 2), whereas bilateral iliac osteotomy with external fixation was done for those operated after the age of three days (Fig. 3).

The second stage was done between 2 to 3 years of age. In this stage, reimplantation of the ureters (Cohen type) are done, based on the results of the preoperative evaluation by intravenous pyelogram (IVP) and micturating cystogram for the presence of vesicoureteric reflux. Additional bladder neck tightening for the outlet was added if the closure pressure was less than $40 \mathrm{~cm}$ of water. 


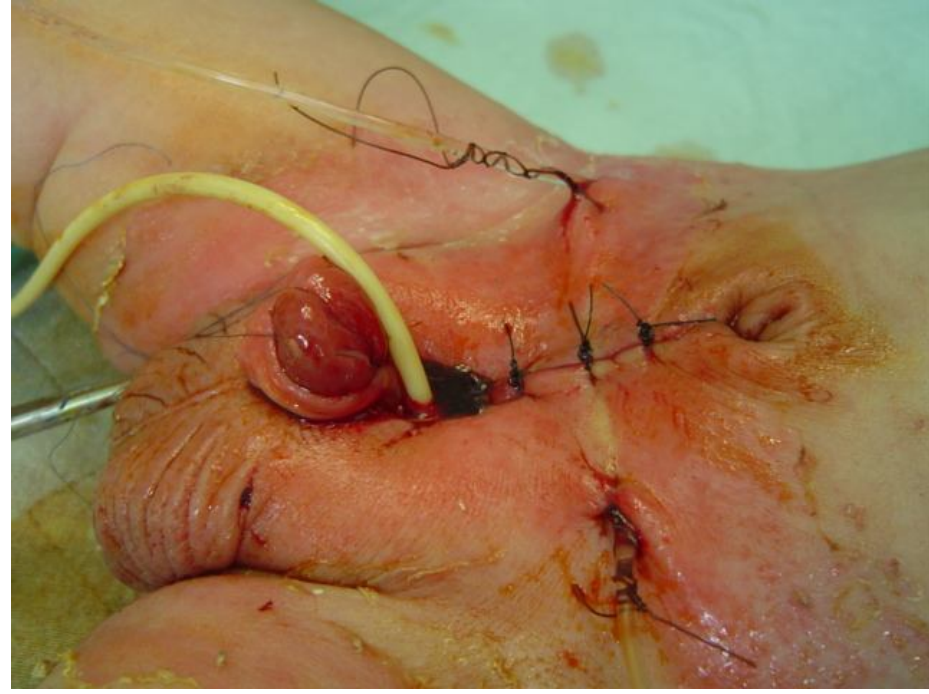

Fig. 2. Closure without osteotomy, done in an ifant 2 days old.

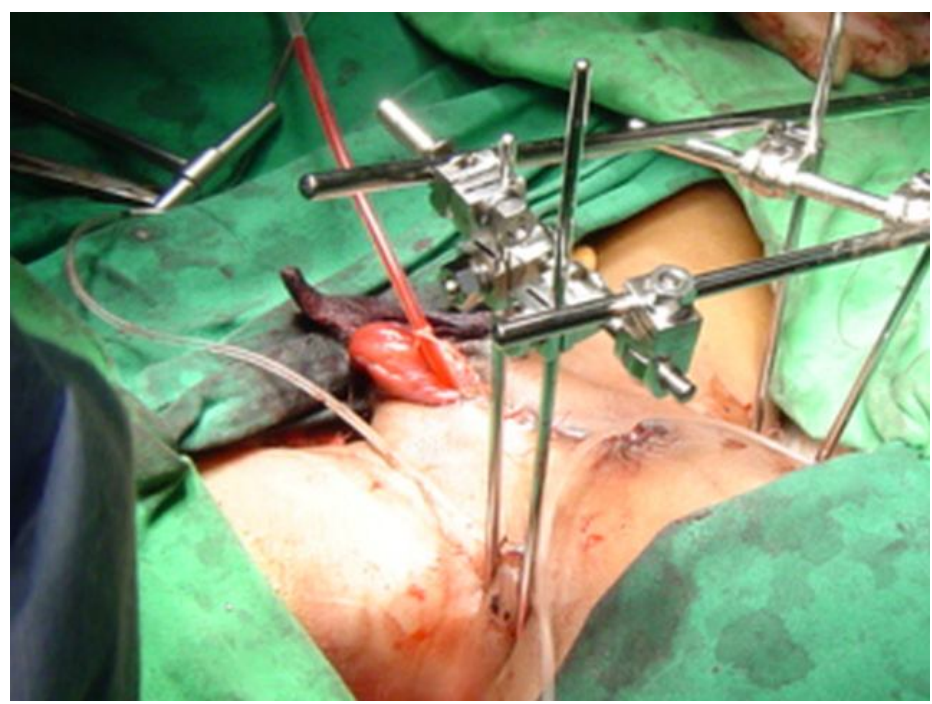

Fig 3. Closure with osteotomy and external fixation.

Bladder augmentation is done if bladder capacity is less than $60 \mathrm{ml}$ with continuous dribbling of urine. This procedure, in three of this study's cases was done: one male patient had ileocystoplasty and two females had cecocystoplasty with exteriorizing the appendix for intermittent catheterization (Mitrofanoff procedure). 
In the last stage, epispadias repair and genitoplasty were done; this will be after 2 years from the last procedure.

\section{Results}

All patients in this study, with bladder exstrophy had undergone all the steps of the procedures.

One patient had complete failure of the initial repair, but responded well after repeating the procedure with bilateral iliac osteotomy a year later; she was initially operated on at the age of seven days without iliac osteotomy.

Vesicoureteric reflux was found in eleven patients, bilateral in nine, one with refluxing duplex system. All had re-implants.

Three patients were found to have dribbling of urine with small, non-compliant bladder; the bladder capacity was less than $40 \mathrm{ml}$ so augmentation ileocystoplasty in one, and cecocystoplasty with external diversion through the appendix (Mitrofanoff appendicovesicostomy) in two were done (Fig. 4). One initially did well with clean intermittent catheterization of the exteriorized appendix, but her renal function deteriorated and eventually she died at the age of nine.

Out of the eleven patients who survived, good results were seen in four patients (dry period more than $3 \mathrm{~h}$ ). They were able to empty their bladder spontaneously by supra pubic pressure, the rest were not, the dry period was less than two hours. All cases had their renal function preserved.

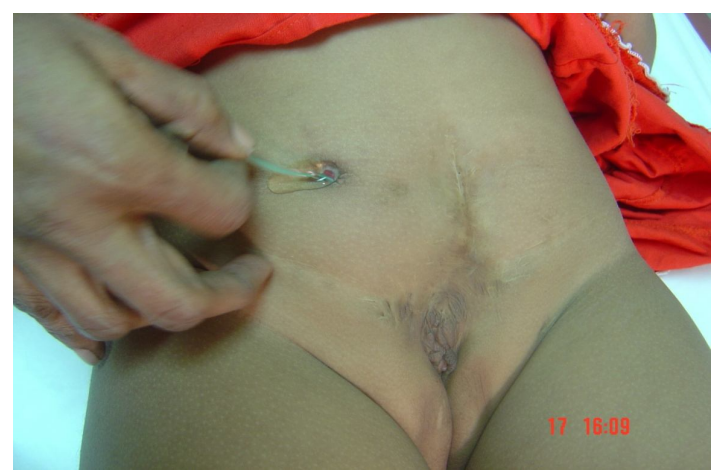

Fig. 4. A female patient's appendix catheterized by the Mitrofanoff procedure. 
The cosmetic appearance looks fair with foreshortened penis in males and thick midline scar in both sexes. Erection and fertility could not be assessed at this stage, it needs further follow-up.

In this study, the mean follow up is 9 years and 3 months.

Few complications were seen and are summarized in Table 2.

All these complications were dealt with individually by closure of the fistula, urethral dilatation, and operative removal or extracorporeal shock wave lithotripsy for the bladder and kidney stones.

Table 2. Post operative complications.

\begin{tabular}{lc}
\hline \multicolumn{1}{c}{ Type of Complications } & No. of Cases \\
\hline Urinary fistula & 4 \\
Urethral stricture & 3 \\
Bladder stone & 4 \\
Bilateral Kidney stone & 1 \\
Failure of initial repair & 1 \\
Death & 1 \\
\hline
\end{tabular}

\section{Discussion}

The history of the treatment of bladder exstrophy goes back to 1849, where several attempts were made in the management of this anomaly, starting from the application of urinary receptacles by Mackay to various forms of diversion, like ureterosigmoidostomy by Sym in 1852. Then, the urinary diversion with mucosa-to-mucosa uretero-colic anastomosis and tunneling the ureters, were done by Nesbit and Leadbetter. In 1950 continuous efforts and several techniques were described both in terms of reconstruction and diversion aiming to overcome the problems associated with VU reflux, small bladder capacity, incompetent bladder neck and urinary sphincters, pubic bone diastases and epispadias ${ }^{[1,2]}$.

The objectives of the treatment are; closure of the bladder and abdominal wall, maintain urinary continence with preservation of kidney functions, reconstruction of functional and cosmetically acceptable external genitalia ${ }^{[6]}$.

The surgical treatment of bladder exstrophy can be achieved in a single or multiple stages with increasing preference towards the staged approach $^{[7-9]}$. Internal urinary diversion to the sigmoid colon and 
reconstruction of the external genetalia was reported, but it is usually associated with several complications particularly those associated with metabolic disturbances and inability to control bowel motions ${ }^{[10]}$. External diversion with augmentation cecocystoplasty (Mitrofanoff) particularly when the bladder template is small, it may be a reasonable option to avoid control ${ }^{[11]}$.

The management in this study's cases went through, in multiple stages because of the reported increasing success when staging the repair. A failure of one step could lead to entire failure, in addition to the length of the procedure ${ }^{[8,9,12]}$.

There are three factors to be taken during management, they are; continence, protection of the kidneys and the cosmetic appearance of functional genitalia.

Continence depends on the size of the bladder and bladder outlet resistance. The apparently small bladder could be closed primarily without augmentation in the majority of the present study's cases, and it would eventually distend depending on the intravesical pressure and outlet resistance ${ }^{[13]}$. This is facilitated by approximating the pubic bones and reconstructing a bladder outlet between 2.5 and $3.5 \mathrm{~cm}$ in length.

Pubic bones can easily be approximated by interrupted sutures through the pubic bones in neonates before three days of age. After that, pelvic osteotomy with external fixation should be applied to avoid disruption and tear of the stitches. Pelvic osteotomy also facilitates abdominal closure and allows the levator ani and Puborectalis muscles to lend potential support of the bladder outlet, thereby adding resistance to urinary outflow ${ }^{[14,15]}$.

Being familiar with the posterior iliac osteotomy, this procedure was operated on all cases after three days, except one who had a failure of repair.

Deterioration of renal functions may result from ascending infection and vesicoureteric reflux; it can be prevented by early closure, ureteric reimplants and avoiding severe outlet resistance during bladder neck reconstruction. 
Penile lengthening and bladder neck tightening, continent procedure had been incorporated during the first stage with maintenance of the closing intravesical pressure "between 40 to $50 \mathrm{~cm}$ of water"

The size of the bladder might be small initially and bladder compliance can be further reduced as a result of frequent dissection. Those factors play a major role in continuous dribbling and incontinence. In such cases, augmentation cystoplasty would be indicated. Various parts of the gastro intestinal tract can be utilized for augmentation, as the greater curvature of the stomach, a segment of ileum, a patch of colon or the cecum. Each has its own drawbacks, however, the advantage of cecocystoplasty utilizing the appendix for intermittent catheterization is of great advantage ${ }^{[17,18]}$.

The patients in this study with fair and poor results could have a better outcome with strict CIC compliance, as they had good bladder capacity $(>70 \mathrm{~mL})$ with mean urethral length of $2 \mathrm{~cm}$ and mean intravesical closure pressure with $40 \mathrm{~cm}$ of water at bladder closure.

Although, penile erection and fertility cannot be assessed at this stage, penile length looks fair in most cases, with mean penile length 4 $\mathrm{cm}$.

\section{Conclusion}

There is no fixed on standard treatment of bladder exstrophy, but in common with other reports and larger series, it seems that staged reconstruction is an appropriate approach; it can avoid an entire failure. Pelvic osteotomy should be done for all cases to be operated after $72 \mathrm{hrs}$. Augmentation of the bladder can be deferred until a later stage after ureteric reimplants, thus a complete evaluation can be made to avoid metabolic complications.

Prolonged follow up is recommended to see the functional results of this study's repair.

\section{References}

[1] Welch KJ, Randolph JG, Ravitch MM, O’Neill JA, Rowe MI. Pediatric Surgery, 4th ed. Chicago/London: Yearbook Medical Pub Inc. 1986. 1216-1241.

[2] Soper RT, Kilger K. Vesico-intestinal fissure. J Urol 1964; 92: 490-501.

[3] Sahoo SP, Gangopadhyay AN, Sinha CK, Gupta DK, Gopal SC. Covered exstrophy: a rare variant of classical bladder exstrophy. Scand J Urol Nephrol 1997; 31(1): 103-106. 
[4] Baker LA, Gearhart JP: The staged approach to bladder extrophy closure and the role of osteotomies. World J Urol 1998; 16(3): 205-11

[5] Mouriquad PD, Wilcox YD. [Bladder extrophy] Arch Esp Urol 1998, 51(6): 515-526.

[6] Saltzman B, Mininberg DT, Muecke EC. Exstrophy of bladder: evolution of management. Urology 1985; 26(4): 383-388.

[7] Oesch I, Jeffs R. [Staged functional closure of bladder exstrophy (author's transl)] $Z$ Kinderchir 1981; 33(1): 74-83.

[8] Baird AD, Nelson CP, Gearhart JP. Modern staged repair of bladder extrophy: A contemporary series. J Pediatr Urol 2007; 3(4): 311-315.

[9] Purves JT, Baird AD, Gearhart JP. The modern staged repair of bladder extrophy in the female: A contemporary study. J Pediatr Urol 2008; 4(2): 150-153.

[10] Sujijantararat P, Chotivichit A. Surgical reconstruction of exstrophy-epispadius complex: analysis of 13 patients. Int J Urol 2002; 9(7): 377-384.

[11] Stien R, Fish M, Black P, Hohenfllner R. Stratigies for reconstruction after unsuccessful or unsatisfactory primary treatment of patients with bladder extrophy or incontinent epispadius. J Urol 1999; 162(5): 1706-1707.

[12] El-Sherbiny MT, Hafez AT, Ghoneim MA. Complete repair of exstrophy: further experience with neonates and children after failed initial closure. J Urol 2002; 168(4 Pt2): 1692-1694.

[13] Bhatnagar V, Lal R, Agarwala S, Mitra DK. Bladder neck repair in urinary bladder exstrophy. Pediatr Surg Int 1999; 15(3-4): 290-293.

[14] Sussman JS, Sponseller PD, Gearhart JP, Valdevit AD, Kier-York J, Chao EY. A comparison of methods of repairing the symphysis pubis in bladder exstrophy by tensile testing. Br J Urol 1997; 79(6): 979-984.

[15] Aadalen RJ, O'Phelan EH, Chisholm TC, McParland FA Jr, Sweetser TH Jr. Exstrophy of the bladder: long-term results of bilateral posterior iliac osteotomies and twostage anatomic repair. Clin Orthop Relat Res 1980; (151): 193-200.

[16] Lottmann HB, Melin Y, Cendron M, Lombrail P, Beze-Beyrie P, Cendron J. Bladder extrophy: evaluation of factors leading to continence with spontaneous voiding after staged reconstruction. J Urol 1997; 158(3 Pt 2): 1041-1044.

[17] Bhatnagar V, Dave S, Agarwala S, Mitra DK. Augmentation colocystoplasty in bladder exstrophy. Pediatr Surg Int 2002; 18(1): 43-49.

[18] Sumfest JM, Burns MW, Mitchell ME. The Mitrofanoff principle in urinary reconstruction. J Urol 1993; 150(6): 1875-1878. 


\section{العلاج المرحلي لحالات بروز المثانة البولية}

\section{جمال صديق كمال}

قسم الجراحة ، كلية الطب ، جامعة الملك عبد العزيز

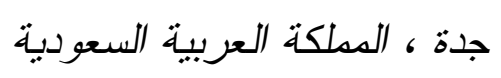

العستخلص. من أحد العيوب الخلقية النادرة، بروز المثانة البولية

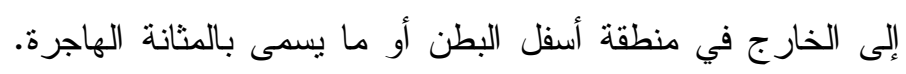

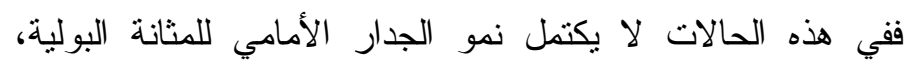

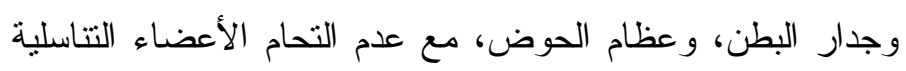

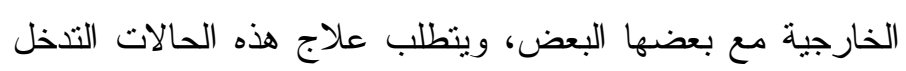

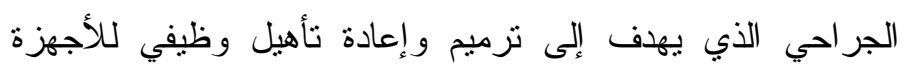

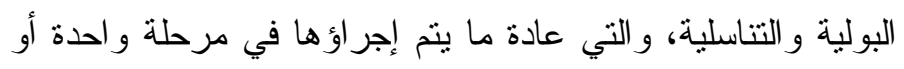

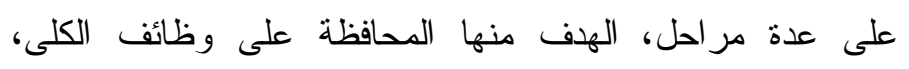
وتحسين القدرة على التحكم في خروج البول والقيام بالوظائف الجنسية مع المحافظة على الثكل الخارجي. فيما بين العام .

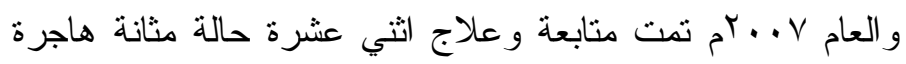

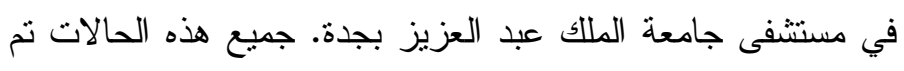

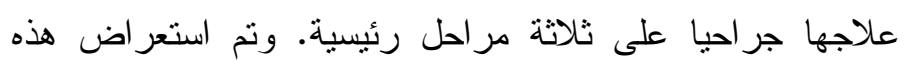

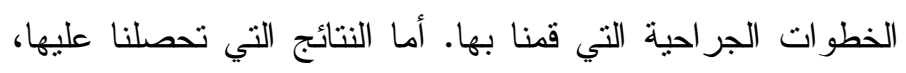

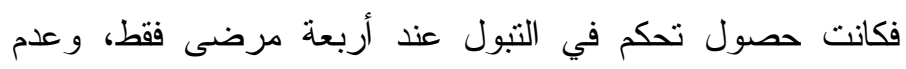

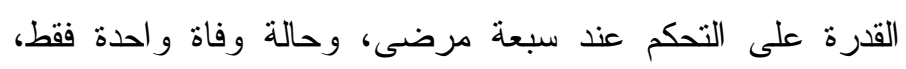
وكانت هناك مضاعفات أخرى أثناء العلاج تم التطرق لها. 